\title{
Lactobacillus spp. reduces ethanol-induced liver oxidative stress and inflammation in a mouse model of alcoholic steatohepatitis
}

\author{
PEI-SHAN HSIEH, CHING-WEI CHEN, YI-WEI KUO and HSIEH-HSUN HO \\ Glac Biotech Co., Ltd., Tainan 74442, Taiwan, R.O.C.
}

Received February 14, 2020; Accepted August 19, 2020

DOI: $10.3892 / \mathrm{etm} .2021 .9619$

\begin{abstract}
Alcoholic steatohepatitis (ASH) is a complex multifactorial disease that can lead to liver fibrosis and cirrhosis if not treated promptly. Alcohol-induced oxidative stress and inflammation are the main factors that cause steatohepatitis and liver injury; however, probiotic bacteria in the gastrointestinal tract have been revealed to regulate immune responses and reduce oxidative stress, suggesting that functional probiotics could help to prevent ASH and liver injury. Despite numerous reports on the interactions between ASH and probiotics, the mechanisms underlying probiotic-mediated liver protection remain unknown. Therefore, the aim of the present study was to screen probiotics with high antioxidant capacity and investigate the ability of different probiotic combinations to reduce alcoholic liver disease (ALD) in a mouse model. It was identified that Lactobacillus plantarum (TSP05), Lactobacillus fermentum (TSF331) and Lactobacillus reuteri (TSR332) neutralized free radicals and displayed high antioxidant activity in vitro. In addition, these three functional probiotic strains protected mice from alcohol-induced liver injury in vivo. Mice treated with the probiotics demonstrated significantly lower alanine aminotransferase, aspartate aminotransferase and triglyceride levels, which were associated with the downregulation of the proinflammatory cytokines TNF- $\alpha$ and IL-6. Furthermore, probiotic treatment upregulated glutathione and glutathione peroxidase activity, which are bioindicators of oxidative stress
\end{abstract}

Correspondence to: Dr Hsieh-Hsun Ho, Glac Biotech Co., Ltd., Fourth floor, 17 Guoji Road, Xinshi, Tainan 74442, Taiwan, R.O.C. E-mail: sam.ho@bioflag.com.tw

Abbreviations: ALD, alcoholic liver disease; ALT, alanine aminotransferase; ASH, alcoholic steatohepatitis; AST, aspartate aminotransferase; CFU, colony-forming unit; DPPH, Diphenyl picryl hydrazyl; FRAP, ferric reducing antioxidant power; GSH, glutathione; GPx, glutathione peroxidase; H\&E, hematoxylin and eosin; LAB, lactic acid bacteria; LGG, Lactobacillus rhamnosus GG; MRS, de Man, Rogosa, and Sharpe; ROS, reactive oxygen species; TG, triglyceride; GRAS, generally recognized as safe

Key words: ALD, antioxidant, anti-inflammatory, Lactobacillus plantarum, Lactobacillus fermentum, Lactobacillus reuteri in the liver. Collectively, the present results indicated that Lactobacillus strains TSP05, TSF331 and TSR332 reduced oxidative stress and inflammatory responses, thus preventing ASH development and liver injury.

\section{Introduction}

Chronic alcohol abuse frequently leads to alcoholic steatohepatitis (ASH) in the liver, with subsequent liver fibrosis and cirrhosis (1). Alcoholic cirrhosis causes $\sim 1$ million mortalities per year globally, accounting for $1 / 2$ of all cirrhosis-related mortality, while alcohol-related hepatocellular carcinoma is responsible for a further 80,000 deaths (1). The World Health Organization reported that individuals who consume excess alcohol are at a high risk of alcoholic liver disease (ALD) and that $\sim 6 \%$ of all global mortalities can be attributed to alcohol consumption (2-4); thus, the issue of alcohol abuse requires immediate attention.

The liver is the main organ involved in alcohol metabolism, in which two major enzymes, alcohol dehydrogenase and acetaldehyde dehydrogenase, participate in the oxidative pathway that converts ethanol to acetaldehyde and causes tissue injury due to the production of reactive oxygen species (ROS) $(5,6)$. Chronic alcohol abuse has been reported to result in ROS overproduction and to interfere with lipid metabolism in the liver, leading to ROS-mediated liver injury (7). In addition, the production of large quantities of ROS by ethanol metabolism may damage the intestinal barrier, leading to barrier leakage and allowing endotoxins and metabolites secreted by gram-negative bacteria to reach the liver portal circulation via the gut-liver axis, which promotes inflammation and ultimately results in ALD or ASH (6-9).

Certain probiotics have been reported to exert beneficial effects against ALD and ASH $(7,10)$; for example, the Lactobacillus (L.) rhamnosus GG (LGG) strain is often used for liver protection (11). Forsyth et al (11) revealed that LGG supplementation may ameliorate intestinal and liver oxidative stress, improve ethanol-induced gut leakiness, and reduce inflammatory responses, while Wang et al (12) reported that L. rhamnosus B10 may decrease the relative liver index by enhancing superoxide dismutase activity and reducing ROS-mediated liver injury. Thus, these findings suggest that $L$. strains could enhance antioxidant activity to improve ALD and hepatitis; however, the mechanism underlying probiotic-mediated liver protection is yet to be elucidated. 
The present study hypothesized that probiotics with antioxidant capacity could reduce alcohol-induced oxidative stress and ultimately liver damage. Therefore, the current study screened probiotics with high antioxidant capacity and investigated the ability of different probiotic combinations to reduce $A L D$ in a mouse model.

\section{Materials and methods}

Isolation, identification and culture of bacterial strains. A total of 12 lactic acid bacteria (LAB) strains were isolated from the intestines of healthy individuals by Glac Biotech Co., Ltd., including three L. rhamnosus strains (gl-105, gl-165 and gl-201), two L. paracasei strains (gl-106 and gl-156), two Enterococcus faecium strains (gl-212 and gl-213), L. casei subsp.casei (gl-217),L.gasseri (gl-102), L.plantarum (TSP05), L. fermentum (TSF331) and L. reuteri (TSR332). TSP05 was isolated from pickled vegetables, while TSF331 and TSR332 were isolated from the intestines of healthy individuals. These samples included adult stool and pickled vegetables for isolation, which were mixed in 1\% PBS (Sigma-Aldrich; Merck $\mathrm{KGaA}$ ). The sample mixtures were plated onto MRS medium plate (Difco; BD Biosciences). After $48 \mathrm{~h}$ incubation, individual colonies were found growing on the plate. The colonies and bacterial strains were identified using their entire $16 \mathrm{~S}$ rDNA sequences as described previously (13-15) and using the National Center for Biotechnology Information nucleotide Basic Local Alignment Search Tool (NCBI; https://www.ncbi. nlm.nih.gov/). Strains TSP05, TSF331 and TSR332 were each successfully activated three times via incubation in de Man, Rogosa and Sharpe (MRS) broth (Difco; BD Biosciences) at $37^{\circ} \mathrm{C}$ for $24 \mathrm{~h}$ and then centrifuged at $10,000 \mathrm{x}$ at $4^{\circ} \mathrm{C}$ for $10 \mathrm{~min}$. The pellets were washed twice with PBS and strains were mixed in equal proportions (1:1) before being orally administered to mice at a dosage of $8.2 \times 10^{9}$ colony-forming units (CFU) per $\mathrm{kg}$ of body weight.

Diphenyl picryl hydrazyl (DPPH) radical-scavenging activity assay. DPPH radical-scavenging activity assays (Sigma-Aldrich; Merck KGaA) were performed according to the method by Xing et al (16). Briefly, $150 \mu \mathrm{l}$ of bacterial cultured solution $\left(1 \times 10^{8} \mathrm{CFU} / \mathrm{ml}\right)$ was mixed with $150 \mu \mathrm{l}$ DPPH solution $(0.2 \mathrm{mM})$ and incubated at $25^{\circ} \mathrm{C}$ in the dark for $30 \mathrm{~min}$. Distilled water $(150 \mu \mathrm{l})$ was used as a blank and $2 \mu \mathrm{g} / \mathrm{ml}$ vitamin $\mathrm{C}$ was used as a positive control. DPPH scavenging was determined by measuring the absorbance (ABS) at $517 \mathrm{~nm}$ (BioPhotometer; Eppendorf) and the radical-scavenging capacity was quantified according to the following formula: DPPH radical-scavenging capacity $(\%)=\mathrm{ABS}_{\text {control }}-\mathrm{ABS}_{\text {sample }} / \mathrm{ABS}_{\text {control }} \times 100$; where $\mathrm{ABS}_{\text {control }}$ and $\mathrm{ABS}_{\text {sample }}$ represent the $\mathrm{ABS}$ of the negative control and sample at $517 \mathrm{~nm}$, respectively.

Ferric reducing antioxidant power (FRAP) assay. FRAP assays (Sigma-Aldrich; Merck KGaA) were conducted according to the method of Benzie and Strain (17). Briefly, $750 \mu \mathrm{l}$ FRAP solution was heated to $37^{\circ} \mathrm{C}$ in a water bath and then $25 \mu \mathrm{l}$ of bacterial cultured solution and $75 \mu \mathrm{l}$ ultrapure water were added. The mixture was placed in the dark at room temperature for $5 \mathrm{~min}$ and the ABS was measured at $593 \mathrm{~nm}$.
Different $\mathrm{FeSO}_{4} \cdot 7 \mathrm{H}_{2} \mathrm{O}$ concentrations were prepared to construct a standard curve, with vitamin $\mathrm{C}(2 \mu \mathrm{g} / \mathrm{ml})$ as a positive control. The samples were analyzed according to the standard curve and results are expressed as the reducing power $\left(\mu \mathrm{g} / \mathrm{ml} \mathrm{Fe}^{2+}\right)$.

Gastric acid and bile tolerance. Gastric acid and bile tolerance was assessed according to the method described by Hyronimus et al (18) and Hassanzadazar et al (19). Activated probiotics were added to eight tubes, one of which was used to count the number of CFUs $\left(1 \times 10^{9} \mathrm{CFU} / \mathrm{ml}\right)$ at $0 \mathrm{~h}$, while the others were centrifuged at $1,770 \mathrm{xg}, 4^{\circ} \mathrm{C}$ for $10 \mathrm{~min}$. Each pellet was mixed well with $5 \mathrm{ml}$ MRS broth $(\mathrm{pH} 3.5)$ and incubated at $37^{\circ} \mathrm{C}$ for $1-3 \mathrm{~h}$, with CFUs counted (plate count) in one tube per hour. The final four tubes were centrifuged at $1,770 \mathrm{x} \mathrm{g}$ $4^{\circ} \mathrm{C}$ for $10 \mathrm{~min}$ before $0.3 \%$ bovine bile (Sigma-Aldrich; Merck $\mathrm{KGaA}$ ) in MRS broth was added and the tubes were incubated at $37^{\circ} \mathrm{C}$ for $4-7 \mathrm{~h}$. CFUs were then enumerated in one tube per hour for 4-7 h.

Intestinal adhesion assay. The human intestinal epithelial colorectal adenocarcinoma cell line Caco-2 was obtained from the Bioresource Collection and Research Center BCRC and cultured according to BCRC guidelines. A sterilized cover slip was placed in the well of a 6-well dish and incubated at $37^{\circ} \mathrm{C}$, $5 \% \mathrm{CO}_{2}$ for 3 days with Caco- 2 cells in minimum essential medium supplemented with $10 \%$ FBS (Merck KGaA) and $1 \%$ penicillin-streptomycin (GE Bio-Science). The medium was removed (cell density almost $1.2 \times 10^{6}$ cells) and the wells were washed twice with PBS before $1.5 \mathrm{ml}$ bacterial suspension $\left(1 \times 10^{9} \mathrm{CFU} / \mathrm{ml}\right)$ and $1.5 \mathrm{ml}$ MRS medium were added to each well and incubated at $37^{\circ} \mathrm{C}$ and $5 \% \mathrm{CO}_{2}$ for $1-4 \mathrm{~h}$. The cells were then washed twice with sterile PBS and fixed with $10 \%$ methanol at $25^{\circ} \mathrm{C}$ for $10 \mathrm{~min}$. The cells were subjected to Gram staining at $25^{\circ} \mathrm{C}$ for $15 \mathrm{~min}$ and enumerated using a light microscope (Nikon Corporation) at 15x100 magnification.

Experimental animals. Male C57B/6N mice (age, 7 weeks; weight, 20-22 g) were purchased from BioLASCO Taiwan. All mice were housed in plastic cages and fed sterilized food and water under $55 \pm 5 \%$ humidity, controlled temperature $\left(22 \pm 2^{\circ} \mathrm{C}\right)$ and a 12-h light/dark cycle, and were acclimated for 1 week prior to experiments. On treatment day 0 , the mice were randomly allocated to the following six groups ( $n=7$ mice/group): i) Control group, fed a regular diet; ii) group A, fed an ethanol-containing diet (containing 28\% ethanol; Dyets, Inc.); iii) group B, fed an ethanol-containing diet + strain TSP05 8.2x10 ${ }^{9} \mathrm{CFU} / \mathrm{kg}$; iv) group C, fed an ethanol-containing diet + strains TSF331 and TSR332 8.2 $\times 10^{9} \mathrm{CFU} / \mathrm{kg}$; v) group D, fed an ethanol-containing diet + strains TSP05, TSF331 and TSR332 8.2×10 ${ }^{9} \mathrm{CFU} / \mathrm{kg}$; and vi) group E, fed a regular diet + strains TSP05, TSF331 and TSR332 (Fig. 1). Mice in the control and E groups were fed a Lieber-DeCarli liquid diet (Dyets, Inc.) without alcohol ad libitum. To induce alcoholic fatty liver injury, the mice in groups A-D were fed a Lieber-DeCarli liquid diet with alcohol, as described previously (20). Mice were administered with a single $0.2 \mathrm{ml}$ dose of deionized water (control, group A) or $0.2 \mathrm{ml}$ deionized water containing the corresponding probiotic(s) (groups B-E) daily via oral gavage for 4 weeks. Experiments were performed in accordance with protocols approved by the 


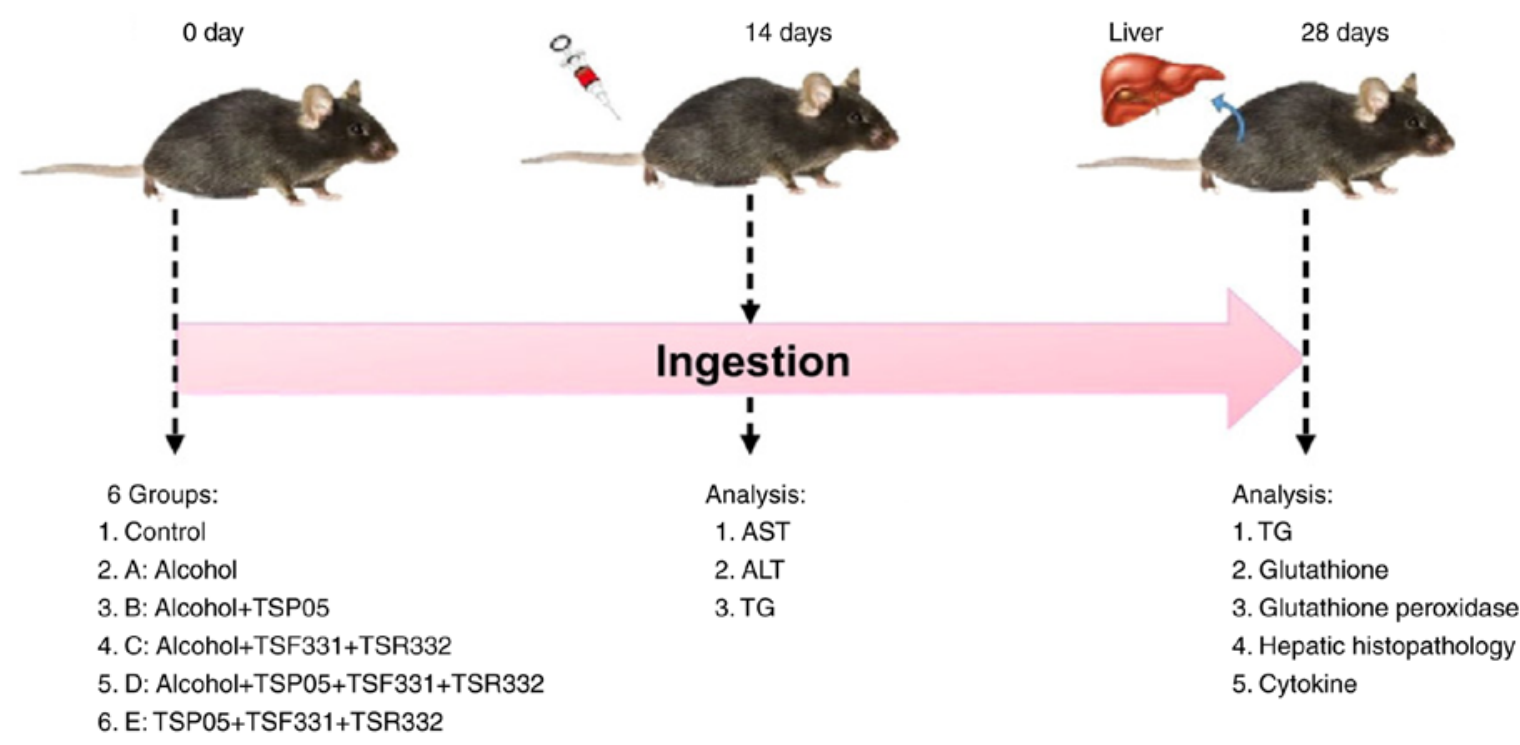

Figure 1. Design of animal experiments. All mice were divide into 6 groups and the experiment was performed for 28 days. Sampling was carried out according to the experimental design on day 0,14 and 28. ALT, alanine aminotransferase; AST, aspartate aminotransferase; TG, triglyceride.

Institutional Animal Care and Use Committee of Hung Kuang University (Taichung, Taiwan).

Mouse serum biochemical analysis. On days 0 , 14 and $28,0.2 \mathrm{ml}$ of blood samples were collected from the eye socket of each mouse $2 \mathrm{~h}$ after oral gavage with a probiotic or water. After incubation for $1 \mathrm{~h}$ at $25^{\circ} \mathrm{C}$, serum was obtained and centrifuged at $2,000 \times \mathrm{g} 4^{\circ} \mathrm{C}$ for $10 \mathrm{~min}$. Serum alanine aminotransferase (ALT), aspartate aminotransferase (AST) and triglyceride (TG) levels were determined using an automatic analyzer (Hitachi 7080; Hitachi, Ltd.) at the National Laboratory Animal Center (Taipei, Taiwan).

Hepatic assays. Mice were weighed and blood samples were collected on day 28 , the mice were euthanized via cervical dislocation and their livers were aseptically dissected out and weighed. Liver-to-body weight ratio: Liver weight/body weight. Each liver was homogenized, and the levels of cytokines [TNF- $\alpha$ (BioLegend, Inc.; cat. no. 430901); IL-6 (BioLegend, Inc.; cat. no. 431301) and IL-10 (BioLegend, Inc.; cat. no. 431411)], glutathione (GSH; BioAssay Systems; cat. no. DIGT-250), GSH peroxidase (GPx; BioAssay Systems; cat. no. EGPX-100) and TGs (Randox Laboratories Ltd.; cat. no. TR1697) were determined using the following commercially available kits: ELISA MAX ${ }^{\mathrm{TM}}$ Standard kit (BioLegend, Inc.; IL-6, cat. no. 431301; IL-10, cat. no. 431411; TNF- $\alpha$, cat. no. 430901), QuantiChrom ${ }^{\mathrm{TM}}$ GSH assay kit (BioAssay Systems; cat. no. 75877-994), EnzyChrom ${ }^{\mathrm{TM}}$ GPx assay kit (BioAssay Systems; cat. no. 75878-136) and Randox TG assay kit (Randox Laboratories, Ltd.; cat. no. TR3823) according to the manufacturer's instructions.

Histological analysis. Liver tissues were fixed with $10 \%$ buffered formalin at room temperature for $8 \mathrm{~h}$, dehydrated using an alcohol gradient $(80 \%$ for $1 \mathrm{~h}, 95 \%$ for $3 \mathrm{~h}$ and $100 \%$ for $4 \mathrm{~h}$ ) and embedded in paraffin wax. Then, tissues were cut into $5-\mu \mathrm{m}$ sections and stained with H\&E at room temperature. The staining steps were as follows, hematoxylin solution for
$10 \mathrm{~min}$, water for $10 \mathrm{~min}, 0.5 \% \mathrm{HCl}$ for $5 \mathrm{sec}$, running water for $30 \mathrm{~min}, 0.5 \%$ eosin solution for $2 \mathrm{~min}, 80 \%$ alcohol for $30 \mathrm{sec}, 90 \%$ alcohol for $30 \mathrm{sec}, 100 \%$ alcohol for $30 \mathrm{sec}$, xylene:alcohol (1:1) for $30 \mathrm{sec}$ and xylene $30 \mathrm{sec}$. To histologically evaluate liver injury, the slides were examined and images were captured under a bright-field light microscope at 10x20 magnification (TE2000-S; Nikon Corporation).

Statistical analysis. Data are presented as the mean \pm SEM obtained from three repeats of per sample. All values from different treatment groups were compared using SPSS 17.0 (SPSS, Inc.), analysing with one-way ANOVAs followed by post-hoc Tukey's tests. $\mathrm{P}<0.05$ was considered to indicate a statistically significant difference.

\section{Results}

In vitro determination of $L A B$ strain antioxidant activities. The present study screened the antioxidant activity of $12 \mathrm{LAB}$ strains. The three strains with the highest antioxidant activities were TSP05, TSF331 and TSR332, which demonstrated DPPH radical-scavenging capacities of 13.6, 13.5 and $13.2 \%$, respectively (Fig. 2A), with a 1.2-fold difference between the third (TSR332) and fourth (gl-201) highest strains. Similarly, the top three strains in the FRAP test were TSF331, TSR332 and TSP05, which had antioxidant activities of 138.2, 135.8 and $110.8 \mu \mathrm{g} / \mathrm{ml} \mathrm{Fe}^{2+}$, respectively (Fig. 2B), with a 1.6-fold difference between the third (TSP05) and fourth (gl-201) highest strains. Based on these results, the three strains with the highest antioxidant activity, TSP05, TSF331 and TSR332, were selected for the in vivo study.

Gastric acid and bile tolerance of potential probiotics and their intestinal adhesion ability. Strains TSP05, TSF331 and TSR332 were resistant to gastric acid ( $\mathrm{pH}$ 3.5) in MRS medium for $3 \mathrm{~h}$, displaying viable counts of $2.32 \times 10^{8}, 4.45 \times 10^{9}$ and $1.93 \times 10^{9} \mathrm{CFU} / \mathrm{ml}$, respectively. After treatment with $0.3 \%$ bile for $4 \mathrm{~h}$ (Equivalent to $7 \mathrm{~h}$ of reaction), the same strains displayed 

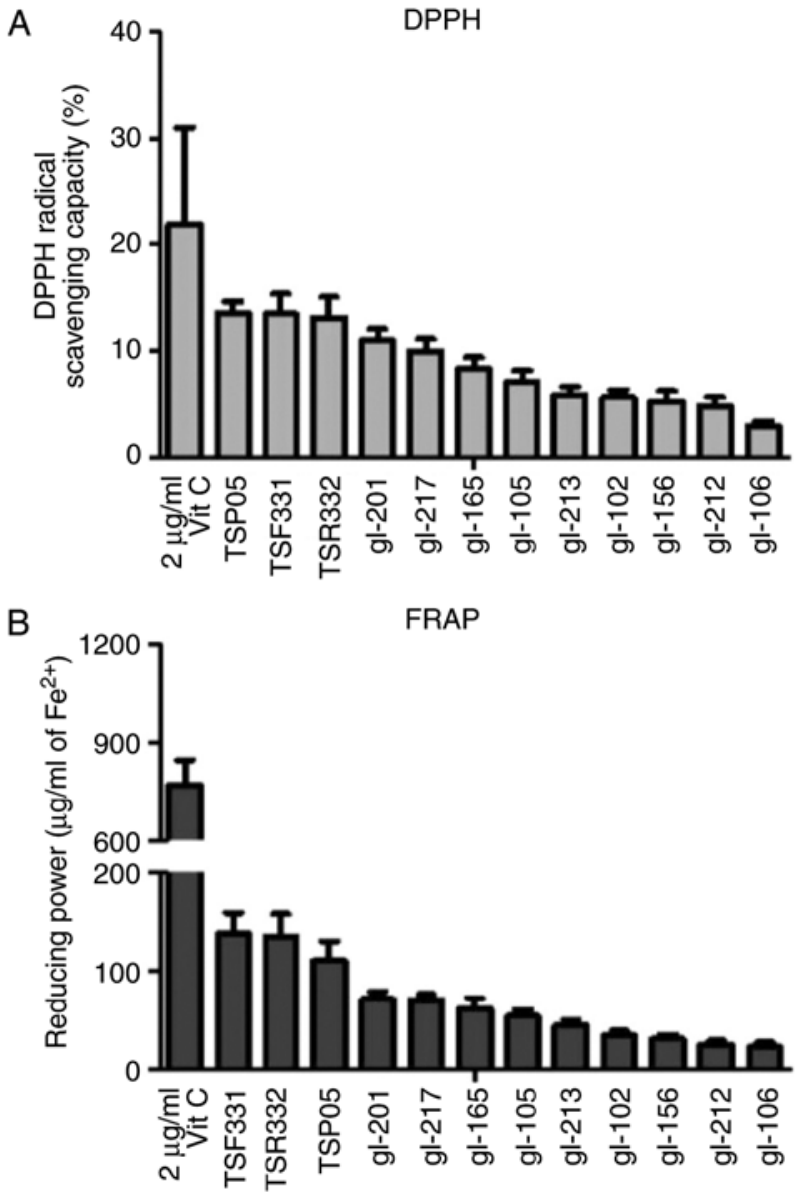

Figure 2. Screening of probiotic antioxidant activities. (A) DPPH assay. (B) FRAP assay. Vit C $(2 \mu \mathrm{g} / \mathrm{ml})$ was used as a positive control. Data are presented as the mean \pm SEM $(\mathrm{n}=3)$. DPPH, diphenyl picryl hydrazyl; FRAP, ferric reducing antioxidant power; Vit $\mathrm{C}$, vitamin $\mathrm{C}$.

viable counts of $2.66 \times 10^{7}, 2.59 \times 10^{9}$ and $4.74 \times 10^{8} \mathrm{CFU} / \mathrm{ml}$, respectively (Fig. S1). To estimate the potential intestinal efficacy of TSP05, TSF331 and TSR332, the current study microscopically assessed their adhesiveness, demonstrating counts of 150.33 , 236.67 and 990.07 CFU/area, respectively (Fig. S2), suggesting that TSR332 exhibited higher intestinal adherence compared with the other two probiotics.

Biochemical indicators of liver function. ALT and AST biochemical values are the main indicators for evaluating liver function (4). Mice on the ethanol diet (group A) had significantly higher $\left.{ }^{\# \# \# ~} \mathrm{P}<0.001\right)$ ALT levels on days 14 and 28 (57.38 \pm 18.21 and $48.67 \pm 7.95 \mathrm{U} / 1$, respectively) compared with those of the control group $(16.65 \pm 3.10$ and $17.98 \pm 4.17 \mathrm{U} / 1$, respectively) (Fig. 3A). However, serum ALT levels on days 14 and 28 were significantly lower in group B (35.96 \pm 6.28 and $34.91 \pm 12.60 \mathrm{U} / 1$, respectively), group $C$ (33.01 \pm 5.91 and $30.64 \pm 10.01 \mathrm{U} / 1$, respectively) and group D (27.77 \pm 3.79 and $25.32 \pm 8.69 \mathrm{U} / 1$, respectively) compared with those in group $\mathrm{A}\left({ }^{*} \mathrm{P}<0.05,{ }^{* *} \mathrm{P}<0.01\right.$ and ${ }^{* * *} \mathrm{P}<0.001$, respectively), with group $\mathrm{D}$ displaying the most effective results.

Alcohol-induced AST levels in group A on days 14 and 28 (72.74 \pm 14.53 and $88.98 \pm 29.45 \mathrm{U} / 1$, respectively) were significantly higher $\left({ }^{\# \#} \mathrm{P}<0.01\right.$ and ${ }^{\#} \mathrm{P}<0.05$, respectively) compared with those in the control group $(46.50 \pm 6.20$ and $51.62 \pm 1$
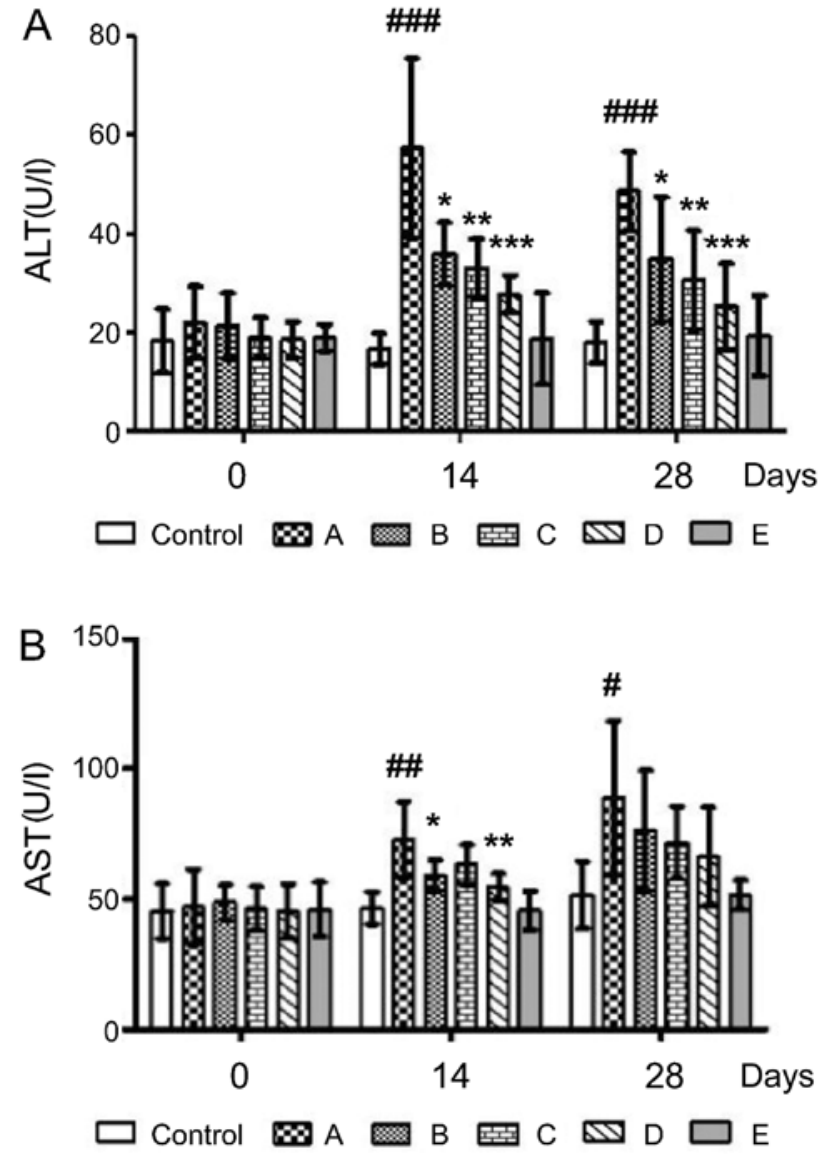

Figure 3. Biochemical indicators of liver function. Effects of probiotics on serum (A) ALT and (B) AST concentrations in alcohol-induced liver injury model mice on days 14 and 28. A, alcohol; B, alcohol + TSP05; C, alcohol + TSF331 + TSR332; D, alcohol + TSP05 + TSF331 + TSR332; E, TSP05 + TSF331 + TSR332. ${ }^{\#} \mathrm{P}<0.05,{ }^{\# \#} \mathrm{P}<0.01,{ }^{\# \#} \mathrm{P}<0.001$ vs. control; ${ }^{*} \mathrm{P}<0.05,{ }^{* *} \mathrm{P}<0.01,{ }^{* * *} \mathrm{P}<0.001$ vs. group A. ALT, alanine aminotransferase; AST, aspartate aminotransferase; TSP05, Lactobacillus plantarum; TSF331, Lactobacillus fermentum; TSR332, Lactobacillus reuteri.

$2.80 \mathrm{U} / 1$, respectively) (Fig. 3B). However, AST levels were significantly lower in groups B $(59.09 \pm 5.84 \mathrm{U} / \mathrm{l})$ and D $(54.73 \pm 5.04 \mathrm{U} / 1)$, respectively compared with those in group A on day 14. Thus, the probiotic combination could decrease ALT and AST on day 14.

Effects of probiotics on serum and hepatic TG content. TG content is one of the common indices used to evaluate fat metabolism (9). The serum TG levels of the mice in each group are presented in Fig. 4A. Mice in group A displayed TG levels of 196. $37 \pm 68.09$ and $192.50 \pm 111.51 \mathrm{mg} / \mathrm{dl}$ on days 14 and 28 , respectively, whereas those in group $\mathrm{C}$ had a lower alcohol-induced serum TG content $\left(80.57 \pm 28.50 ;{ }^{*} \mathrm{P}<0.05\right)$ on day 28 . However, mice treated with probiotics demonstrated no significant differences in TG content on day 14 compared with that of group A. In addition, group A had a significantly higher $\left.{ }^{\# \# \#} \mathrm{P}<0.001\right)$ hepatic TG level $(76.35 \pm 10.13 \mu \mathrm{M} / \mathrm{g})$ compared with the control group $(39.13 \pm 5.10 \mu \mathrm{M} / \mathrm{g})$ on day 28 , while the alcohol-induced hepatic TG content was reduced in groups B $(50.20 \pm 6.00 \mu \mathrm{M} / \mathrm{g})$, $\mathrm{C}(48.86 \pm 9.39 \mu \mathrm{M} / \mathrm{g})$ and $\mathrm{D}(50.88 \pm 4.57 \mu \mathrm{M} / \mathrm{g})$, respectively, all compared to that of group $\mathrm{A}\left({ }^{\# \# \#} \mathrm{P}<0.001\right.$, respectively) on day 28 . Therefore, the results suggested that the probiotic combination could effectively decrease the hepatic TG level. 

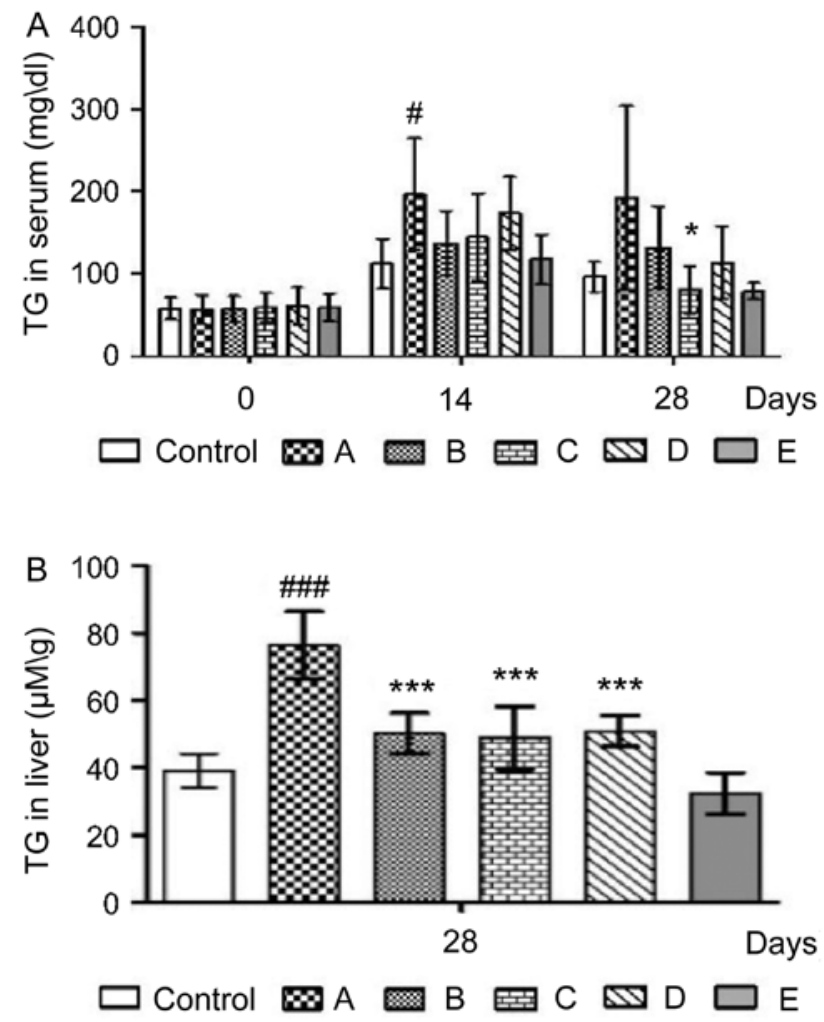

Figure 4. Effects of probiotics on serum and hepatic TG content. Effects of probiotics on TG levels in the (A) serum and (B) liver of alcohol-fed mice. A, alcohol; B, alcohol + TSP05; C, alcohol + TSF331 + TSR332; D, alcohol + TSP05 + TSF331 + TSR332; E, TSP05 + TSF331 + TSR332. ${ }^{\#} \mathrm{P}<0.05,{ }^{\# \# *} \mathrm{P}<0.001$ vs. control; ${ }^{*} \mathrm{P}<0.05,{ }^{* * *} \mathrm{P}<0.001$ vs. group $\mathrm{A}$. TSP05, Lactobacillus plantarum; TSF331, Lactobacillus fermentum; TSR332, Lactobacillus reuteri; TG, triglyceride.

Effects of the probiotics on hepatic antioxidant capacity. To examine whether the three probiotics with high in vitro antioxidant activity, TSP05, TSF331 and TSR332, could affect the intestine and the alcohol-induced oxidative cascade in the livers of mice, the liver GSH concentration and GPx activity were measured (Fig. 5). In group A, alcohol-induced free radicals significantly decreased GSH production by $\sim 36.14 \%$ (from $925.00 \pm 59.62$ to $590.69 \pm 53.24 \mu \mathrm{M} / \mathrm{g}$; ${ }^{\# \# \#} \mathrm{P}<0.001$ ) compared with the control group (Fig. 5A); however, GSH levels were significantly higher in group B $(807.66 \pm 86.87 \mu \mathrm{M} / \mathrm{g})$, group $\mathrm{C}(892.71 \pm 187.88 \mu \mathrm{M} / \mathrm{g})$ and group D $(1,044.10 \pm 192.32 \mu \mathrm{M} / \mathrm{g})$ compared with those in group $\mathrm{A}\left({ }^{*} \mathrm{P}<0.05,{ }^{* *} \mathrm{P}<0.01\right.$ and ${ }^{* * *} \mathrm{P}<0.001$, respectively). Hepatic GPx levels were significantly higher $\left({ }^{* * *} \mathrm{P}<0.001\right)$ in group $\mathrm{B}$ $(54,166.68 \pm 4,007.50 \mathrm{U} / \mathrm{l})$, group C $(70,019.85 \pm 3,612.79 \mathrm{U} / \mathrm{l})$ and group D $(63,869.02 \pm 5,236.38 \mathrm{U} / 1)$ compared with those in group A $(25,003.95 \pm 1,194.51 \mathrm{U} / \mathrm{l})$, and were significantly higher $\left({ }^{\# \# \#} \mathrm{P}<0.001\right)$ ingroupE $(61,000.00 \pm 9,706.00 \mathrm{U} / \mathrm{l})$ compared with those in the control group $(24,341.27 \pm 796.60 \mathrm{U} / 1$; Fig. 5B). Thus, the results indicated that the probiotics combination could induce GPx and consequently improve antioxidant capacity.

Effects of probiotics on hepatic cytokine levels. To evaluate the effects of probiotics on hepatic cytokine levels, the levels of the inflammatory cytokines, TNF- $\alpha$ and IL-6, and the anti-inflammatory cytokine IL-10 were detected. TNF- $\alpha$ and IL-6 were significantly induced in the alcohol-fed groups; however,
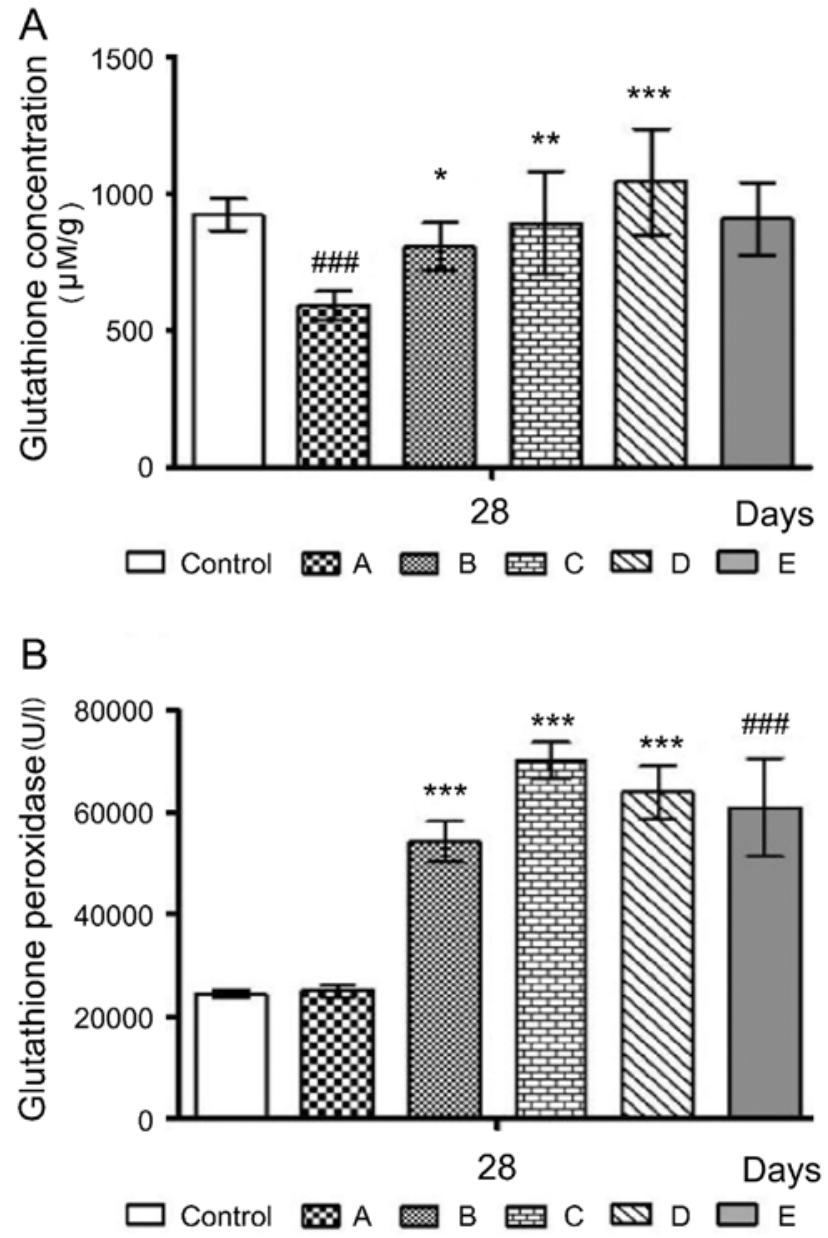

Figure 5. Effects of probiotics on liver antioxidant capacity of alcohol-fed mice on day 28. (A) Glutathione concentration. (B) Glutathione peroxidase activity. A, alcohol; B, alcohol + TSP05; C, alcohol + TSF331 + TSR332; D, alcohol + TSP05 + TSF331 + TSR332; E, TSP05 + TSF331 + TSR332.

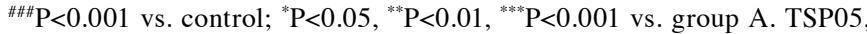
Lactobacillus plantarum; TSF331, Lactobacillus fermentum; TSR332, Lactobacillus reuteri.

TNF- $\alpha$ levels in the probiotic-fed groups B, C and D were 537. $91 \pm 9.40,589.15 \pm 10.57$ and $545.48 \pm 9.09 \mathrm{pg} / \mathrm{ml}$, respectively, lower compared with those in group A $(655.48 \pm 23.35 \mathrm{pg} / \mathrm{ml}$; ${ }^{* * *} \mathrm{P}<0.001,{ }^{* * *} \mathrm{P}<0.001$ and ${ }^{* * *} \mathrm{P}<0.001$ ) (Fig. 6A). Similarly, IL-6 levels were $25.10 \%$ lower in groups D compared with those in group A ( $372.22 \mathrm{pg} / \mathrm{ml}$; "P $<0.05$; Fig. 6B). It was found that group E displayed physiological TNF- $\alpha$ and IL-6 levels comparable with those of the control (Fig. 6A and B), whereas group D had significantly higher IL-10 levels compared with group A (Fig. 6C). Moreover, group E demonstrated the highest IL-10 levels of all groups, indicating that the triple LAB mixture could activate this anti-inflammatory peptide to inhibit alcohol-induced inflammatory responses (Fig. 6C).

Effects of probiotics on fatty liver, body weight and liver-to-body ratio in alcohol-challenged mice. To observe the performance of probiotics in the liver tissue, changes in the histological structure of the livers in the six groups were assessed using $\mathrm{H} \& \mathrm{E}$ staining. Excessive alcohol consumption in group A caused macrovesicular fat accumulation in liver cells, as well as cell degeneration and necrosis (Fig. 7B), which were likely due to 

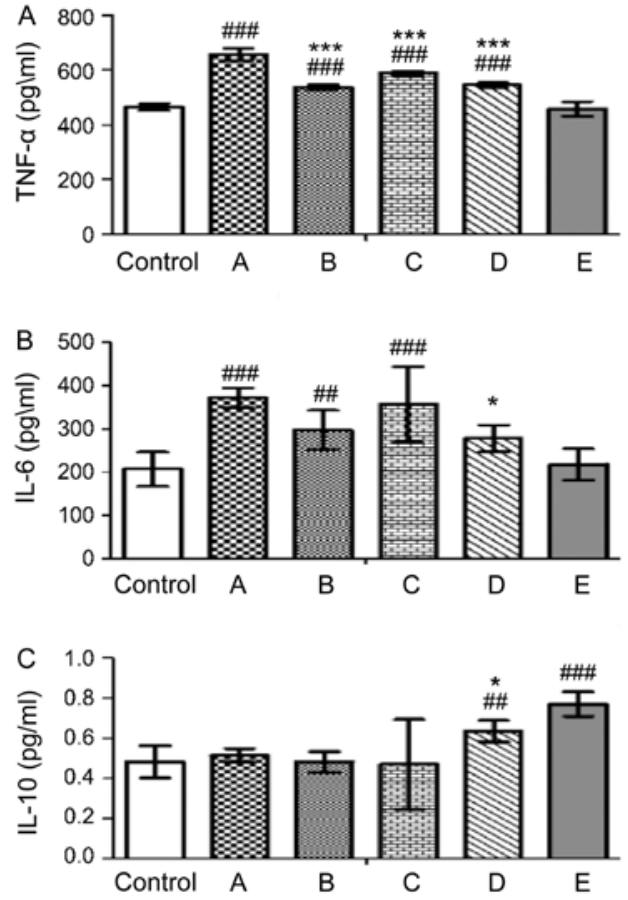

Figure 6. Effects of probiotics on cytokine levels in the liver of alcohol-fed mice on day 28. (A) TNF- $\alpha$, (B) IL-6 and (C) IL-10. A, alcohol; B, alcohol + TSP05; C, alcohol + TSF331 + TSR332; D, alcohol + TSP05 + TSF331 + TSR332; E, TSP05 + TSF331 + TSR332. ${ }^{\# \#} \mathrm{P}<0.01,{ }^{\# \# \#} \mathrm{P}<0.001$ vs. control; ${ }^{*} \mathrm{P}<0.05,{ }^{* * *} \mathrm{P}<0.001$ vs. group A. TSP05, Lactobacillus plantarum; TSF331, Lactobacillus fermentum; TSR332, Lactobacillus reuteri.

inflammatory effects. However, groups B, C and D, which were treated with probiotics, demonstrated a similar liver histology to the control group (Fig. 7C-E), and the triple LAB mixture caused no fatty liver and no histological changes compared with the control group (Fig. 7F). Hence, the probiotic combinations could effectively decrease the accumulation of fat bubbles.

The changes in body weight and the liver-to-body weight ratio were observed in alcohol-challenged mice. Mice in the alcohol-fed groups A $(23.31 \pm 1.48 \mathrm{~g}), \mathrm{B}(22.44 \pm 1.25 \mathrm{~g})$, C $(22.03 \pm 1.51 \mathrm{~g})$ and $\mathrm{D}(23.25 \pm 0.86 \mathrm{~g})$ displayed a significantly lower body weight compared with those in the control group (28.28 $\pm 2.04 \mathrm{~g}$; ${ }^{\# \# "} \mathrm{P}<0.001,{ }^{\# \# "} \mathrm{P}<0.001$ and ${ }^{\# \# "} \mathrm{P}<0.001$, respectively) and in group $\mathrm{E}\left(26.70 \pm 2.24 \mathrm{~g},{ }^{* * *} \mathrm{P}<0.001,{ }^{* * *} \mathrm{P}<0.001\right.$ and ${ }^{* * *} \mathrm{P}<0.001$, respectively) (Fig. 8A). However, no significant differences in the liver-to-body weight ratio were identified between the different groups (Fig. 8B).

\section{Discussion}

Excessive alcohol intake is a major cause of chronic liver disease, and chronic alcohol abuse can cause ROS overproduction and interfere with lipid metabolism in the liver, leading to ROS-mediated liver injury (7). Therefore, the present study screened the in vitro antioxidant activity of 12 generally recognized as safe (GRAS) LAB strains. Of these, strains TSP05, TSF331 and TSR332 were found to display the highest in vitro antioxidant activities, and their dietary supplementation enhanced the liver antioxidant capacity of mice and ameliorated ethanol-induced oxidative stress in vivo. Collectively, the present results indicated that more functional probiotic strains could be discovered using this screening strategy.
Alcohol is metabolized into acetaldehyde, resulting in the production of free radicals and carcinogens, thereby stimulating inflammatory responses to release liver injury indicators (ALT and AST) into the serum (21-24). Oxidative damage has been reported to induce lipid peroxidation, thus disrupting lipid metabolism and affecting liver cells (7,21-23). Since enzymatic and non-enzymatic antioxidant reactions are necessary to protect against oxidative damage, GPx and GSH are commonly used as indicators to evaluate the effect of oxidative stress (23-25). GSH is the most abundant antioxidant in liver cells and prevents damage caused by heavy ethanol consumption (26), while GPx reduces lipid hydroperoxides to their corresponding alcohols and free hydrogen peroxide to water (27). Therefore, high GSH levels and GPx activity can neutralize ROS and prevent oxidative stress $(7,23)$. The present study identified that feeding mice with probiotics (individually and in combination) for 4 weeks significantly increased GSH levels, thus recovering GSH concentrations to a level equivalent to that of the control group. Moreover, the mice administered probiotic combinations demonstrated significantly higher GPx activities, with group E displaying $\sim 3$-fold higher GPx activity compared with the control group. Thus, these probiotic combinations could stimulate the host antioxidant system and reduce the damage caused by alcohol-induced oxidation.

In addition to oxidative stress, inflammation can cause ALD (28). The present results suggested that inflammatory cytokines, such as TNF- $\alpha$ and IL-6, were significantly repressed in group $\mathrm{D}$, which were administered probiotic combinations, whereas no direct inflammatory responses were induced in group E. Notably, levels of the anti-inflammatory peptide IL-10 were significantly higher in groups D and E compared with those in the control group. Therefore, the administration of probiotic combinations not only increased the levels of antioxidant enzymes to protect against alcohol-induced oxidative stress, but also enhanced the anti-inflammatory response in ALD to reduce liver injury and ameliorate lipid peroxidase activity due to chronic alcohol consumption.

The current study established a mouse model of alcoholic fatty liver disease, and hepatoprotective effects were observed in the probiotic-treated groups, with their anti-inflammatory and antioxidant activities demonstrated by investigating TNF- $\alpha$, IL-6 and IL-10 levels, as well as GSH and GPx content. However, it was not possible to examine all signal transduction pathways that may be involved in this mechanism, and additional research is required to further elucidate the molecular mechanism. A possible mechanism could be the production of polyphenols and phenolic-derives by probiotics (29), since L. plantarum has been reported to exert O-glycosidase activity, which can break down flavonoid C-rings at different positions (30). In addition, polyphenol conversion by gut microbiota is usually essential for absorption and biological activities in the human body (30). TSP05, and the combination of TSR332 and TSF331, may exert anti-inflammatory responses via different pathways, as stronger decreases in TNF- $\alpha$ and IL- 6 levels were identified in mice treated with TSP05 compared with in those treated with TSR332 and TSF331. Previous studies have revealed that the liver-protective effects of extra virgin olive oil are due to the downregulation of NF- $\mathrm{KB}$ expression, which acts downstream of TNF- $\alpha$ and IL-6 $(31,32)$. Although the present study did not measure NF- $\kappa B$ levels in the experimental animals, it is 

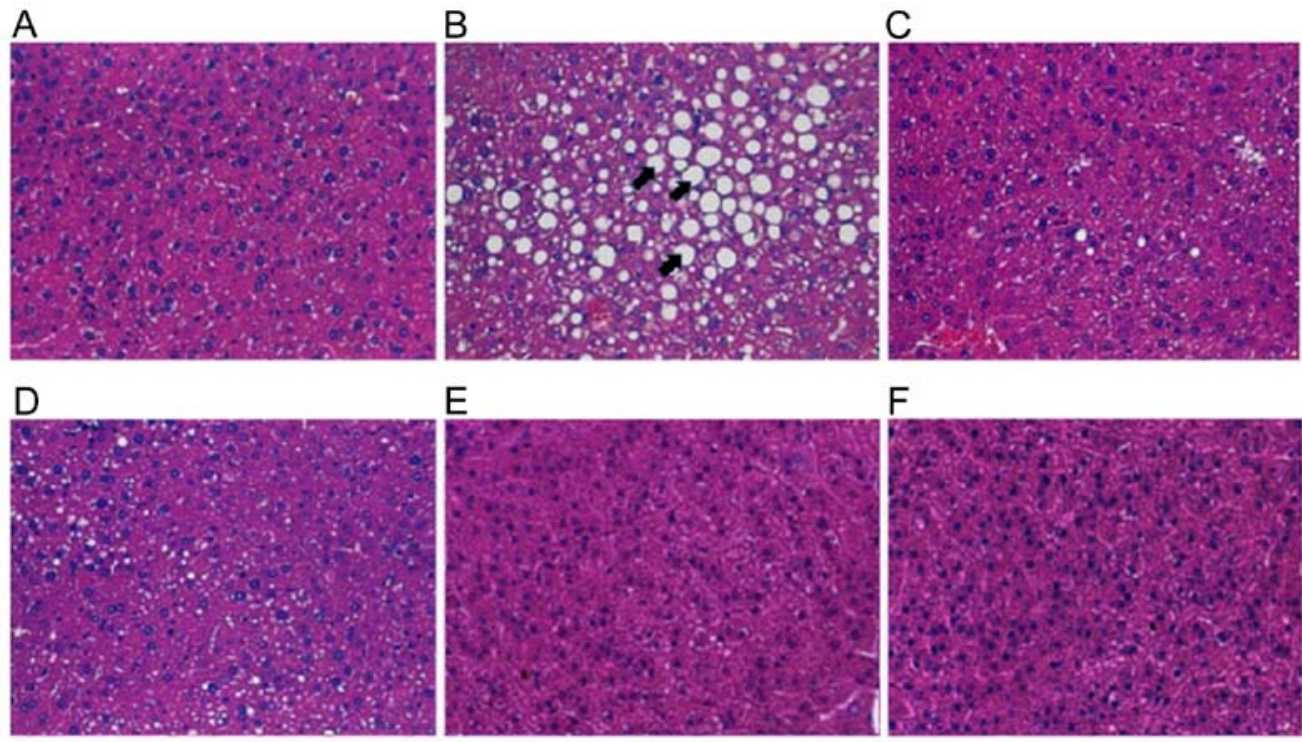

Figure 7. Effects of alcohol and probiotics on hepatic histopathology in alcohol-fed mice. Hematoxylin and eosin staining in (A) control group; (B) Group A, alcohol; (C) Group B, alcohol + TSP05; (D) Group C, alcohol + TSF331 + TSR332; (E) Group D, alcohol + TSP05 + TSF331 + TSR332; and (F) Group E, TSP05 + TSF331 + TSR332. Magnification, x400. Arrows indicates fat inclusions in the liver. TSP05, Lactobacillus plantarum; TSF331, Lactobacillus fermentum; TSR332, Lactobacillus reuteri.
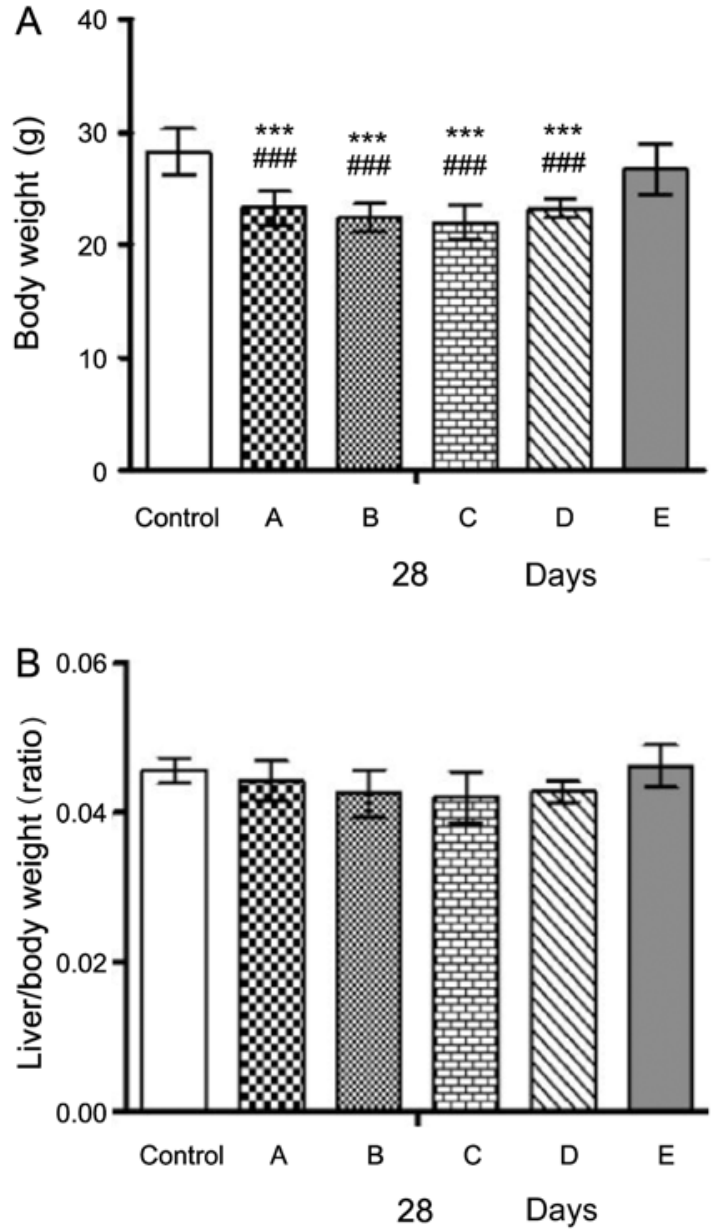

Figure 8. Effects of probiotics on the liver and body weight of alcohol-induced liver injury mouse models on day 28. Changes in (A) body weight and (B) liver/body weight ratio. A, alcohol; B, alcohol + TSP05; C, alcohol + TSF331 + TSR332; D, alcohol + TSP05 + TSF331 + TSR332; E, TSP05 + TSF331 + TSR332. ${ }^{\# \#} \mathrm{P}<0.001$ vs. control; ${ }^{* * *} \mathrm{P}<0.001$ vs. group E. TSP05, Lactobacillus plantarum; TSF331, Lactobacillus fermentum; TSR332, Lactobacillus reuteri. reasonable to assume that $\mathrm{NF}-\kappa \mathrm{B}$ expression may be downregulated as a result of probiotic supplementation. The antioxidant response is regulated by a complex network in which $\mathrm{Nrf} 2$ is a key transcription factor, and previous studies have shown that Nrf2 is activated in the mouse liver by a high-fat diet $(32,33)$. In the current study, strong GPx induction was observed in all probiotic-treated groups and was attributed to antioxidant activity; therefore, future studies should investigate whether GSH and GPx are induced by Nrf2.

Previous studies have reported that probiotics, such as LGG, could effectively improve ALD $(9,28)$. For instance, Forsyth et al (11) found that supplementing rats with LGG $\left(2.5 \times 10^{7} \mathrm{CFU} / \mathrm{ml}\right)$ for 10 weeks improved ALD. Similarly, Bull-Otterson et al (34) increased the LGG dose to $1 \times 10^{9} \mathrm{CFU} / \mathrm{ml}$ over 2 weeks to examine the effects on liver improvement in mice, identifying that LGG altered the intestinal microbiome and reduced alcohol-induced ALT levels by $27 \%$. The present results suggested that alcohol-induced ALT levels were significantly lower in the probiotic-treated groups (B, C and D; $1.6 \times 10^{8} \mathrm{CFU} / \mathrm{ml}$ ) compared with group A. Previously, Kim et al (35) reported that L. fermentum LA12 could improve liver function and hepatic steatosis in rats by restoring the gut barrier, thus preventing endotoxin leakage into the blood. In addition, LA12 $\left(1 \times 10^{9} \mathrm{CFU} / \mathrm{ml} ; 4\right.$ weeks) reduced ALT and AST levels in the serum by 24 and $18 \%$, respectively (35). Similarly, Chiu et al (36) demonstrated that symbiotic (mixture of probiotics and prebiotics) supplementation $\left(2 \times 10^{9} \mathrm{CFU} / \mathrm{ml}\right)$ for 4 weeks could attenuate serum ALT and AST levels by 29 and $13 \%$, respectively. In the present study, the probiotic-treated mice in groups B, C and D displayed lower ALT (by 28, 37 and 48\%, respectively) and AST (by 14,20 and $26 \%$, respectively) levels on day 28 compared with those of group A. Unlike ALT, which is primarily present in the liver, AST is not liver-specific and is also present in the heart, brain and skeletal muscle (37); therefore, probiotics may not completely repress alcohol-induced AST expression. 
Chronic alcohol consumption increases TG levels in the serum and liver, eventually leading to fatty liver disease $(38,39)$. In the current study, the serum TG content did not differ between group A and the control group on day 28, as the standard error in group A was large; however, TG levels were 58\% lower in group $\mathrm{C}$ compared with in group A. Although serum TG levels were not decreased to control levels by the probiotic combinations, there were significantly downregulated alcohol-induced TG levels in the liver by 34, 36 and $33 \%$ in groups B, C and D, respectively. Moreover, histopathological analysis of the liver tissue revealed that treatment with probiotics and their combinations (groups B, C and D) significantly prevented alcohol-induced fat accumulation in the liver.

Collectively, the present results indicated that the LAB strains TSP05, TSF331 and TSR332 and their combinations could be used as supplements to ameliorate ASH and ALD due to their antioxidant and anti-inflammatory activities. Furthermore, these probiotics were demonstrated to protect against ethanol-induced oxidation, reduce gut barrier damage and suppress the inflammatory response. Although the potential of these probiotics warrants confirmation in a human clinical study, antioxidants have been reported to effectively regulate gut permeability and enhance antioxidant activity in patients with ALD (40). The probiotic strains used in the current study are GRAS and have the potential to be used as therapeutic agents in patients with ALD; however, this study is limited by the fact that fecal microbiota were not examined due to inaccurate technology for quantifying and identifying different microbial species.

In conclusion, the present study proposed a novel combination of probiotic $L$. strains TSP05, TSF331 and TSR332 for the improvement of ALD. The current results demonstrated that this combination could alleviate alcohol-induced liver injury and elevate antioxidant activity to attenuate the alcohol-induced oxidative cascade. In addition, these supplements enhanced the anti-inflammatory response to reduce alcohol-induced inflammatory signals. Therefore, this probiotic combination provides a new therapeutic option for treating ALD.

\section{Acknowledgements}

The authors would like to thank the Glac Biotech Co., Ltd. consultant, Dr Hau-Yang Tsen, who provided valuable feedback on the manuscript.

\section{Funding}

No funding was received.

\section{Availability of data and materials}

The datasets used and/or analysed during the current study are available from the corresponding author on reasonable request.

\section{Authors' contributions}

PSH and $\mathrm{HHH}$ designed the study. CWC and YWK performed the experiments and analysed the data. $\mathrm{PSH}, \mathrm{CWC}$ and $\mathrm{HHH}$ wrote the original manuscript. $\mathrm{PSH}, \mathrm{CWC}$ and $\mathrm{HHH}$ revised the manuscript. All authors read and approved the final manuscript.

\section{Ethics approval and consent to participate}

The study protocols were approved by the Institutional Animal Care and Use Committee of Hung Kuang University (ethical approval no. HK-10605).

\section{Patient consent for publication}

Not applicable.

\section{Competing interests}

The authors declare that they have no competing interests.

\section{References}

1. Rehm J and Shield KD: Global alcohol-attributable deaths from cancer, liver cirrhosis, and injury in 2010. Alcohol Res 35: 174-183, 2013.

2. World Health Organization: Global status report on alcohol and health 2014. http://www.who.int/substance_abuse/ publications/global_alcohol_report/msb_gsr_2014_1.pdf.

3. World Health Organization: Global status report on alcohol and health 2018. https://apps.who.int/iris/bitstream/handle/10665/27 4603/9789241565639-eng.pdf.

4. Bajaj JS: Alcohol, liver disease and the gut microbiota. Nat Rev Gastroenterol Hepatol 16: 235-246, 2019.

5. Lieber CS: Role of oxidative stress and antioxidant therapy in alcoholic and nonalcoholic liver diseases. Adv Pharmacol 38: 601-628, 1996

6. Li F, Duan K, Wang C, McClain C and Feng W: Probiotics and alcoholic liver disease: Treatment and potential mechanisms. Gastroent Res Pract 2016: 5491465, 2016.

7. Gu Z, Liu Y, Hu S, You Y, Li W and Wang Y: Probiotics for alleviating alcoholic liver injury. Gastroent Res Pract 2019: 9097276, 2019.

8. Schnabl B and Brenner DA: Interactions between the intestinal microbiome and liver diseases. Gastroenterology 146: 1513-1524, 2014.

9. Zhou $\mathrm{Z}$ and Zhong $\mathrm{W}$ : Targeting the gut barrier for the treatment of alcoholic liver disease. Liver Res 1: 197-207, 2017.

10. Kirpich IA, Solovieva NV, Leikhter SN, Shidakova NA, Lebedeva OV, Sidorov PI, Bazhukova TA, Soloviev AG, Barve SS, McClain CJ and Cave M: Probiotics restore bowel flora and improve liver enzymes in human alcohol-induced liver injury: A pilot study. Alcohol 42: 675-682, 2008.

11. Forsyth CB, Farhadi A, Jakate SM, Tang Y, Shaikh M and Keshavarzian A: Lactobacillus GG treatment ameliorates alcohol-induced intestinal oxidative stress, gut leakiness, and liver injury in a rat model of alcoholic steatohepatitis. Alcohol 43: 163-172, 2009.

12. Wang Y, Gao J, Zhang J and Hu Y: Lactobacillus rhamnosus B10 treatment ameliorates ethanol-induced mouse liver injury by antioxidant pathways. Food Sci 33: 270-274, 2012.

13. Hiraishi A: Direct automated sequencing of $16 \mathrm{~S}$ rDNA amplified by polymerase chain reaction from bacterial cultures without DNA purification. Lett Appl Microbiol 15: 210-213, 1992.

14. Lane DJ: $16 \mathrm{~S} / 23 \mathrm{~S}$ rRNA sequencing. In: Nucleic acid techniques in bacterial systematics. Stackebrandt E and Goodfellow M (eds.) John Wiley and Sons, New York, pp115-175, 1991.

15. Weisburg WG, Barns SM, Pelletier DA and Lane DJ: 16S ribosomal DNA amplification for phylogenetic study. J Bacteriol 173: 697-703, 1991.

16. Xing J, Wang G, Zhang Q, Liu X, Gu Z, Zhang H, Chen YQ and Chen W: Determining antioxidant activities of lactobacilli cell-free supernatants by cellular antioxidant assay: A comparison with traditional methods. PLoS One 10: e0119058, 2015.

17. Benzie IFF and Strain JJ: Ferric reducing/antioxidant power assay: Direct measure of total antioxidant activity of biological fluids and modified version for simultaneous measurement of total antioxidant power and ascorbic acid concentration. Methods Enzymol 299: 15-27, 1999.

18. Hyronimus B, Le Marrec C, Hadj Sassi A and Deschamps A: Acid and bile tolerance of spore-forming lactic acid bacteria. Int J Food Microbiol 61: 193-197, 2000. 
19. Hassanzadazar H, Ehsani A, Mardani K and Hesari J: Investigation of antibacterial, acid and bile tolerance properties of lactobacilli isolated from Koozeh cheese. Vet Res Forum 3: $181-185,2012$

20. Lieber CS and DeCarli LM: Liquid diet technique of ethanol administration: 1989 update. Alcohol Alcohol 24: 197-211, 1989.

21. Guo R and Ren J: Alcohol and acetaldehyde in public health: From marvel to menace. Int J Environ Res Public Health 7 : $1285-1301,2010$

22. Tuma DJ and Casey CA: Dangerous byproducts of alcohol breakdown-focus on adducts. Alcohol Res Health 27: 285-290, 2003.

23. Li S, Tan HY, Wang N, Zhang ZJ, Lao L, Wong CW and Feng Y: The role of oxidative stress and antioxidants in liver diseases. Int J Mol Sci 16: 26087-26124, 2015.

24. Mallikarjuna K, Shanmugam KR, Nishanth K, Wu MC, Hou CW, Kuo CH and Reddy KS: Alcohol-induced deterioration in primary antioxidant and glutathione family enzymes reversed by exercise training in the liver of old rats. Alcohol 44: 523-529, 2010.

25. Dey A and Lakshmanan J: The role of antioxidants and other agents in alleviating hyperglycemia mediated oxidative stress and injury in liver. Food Funct 4: 1148-1184, 2013.

26. Pompella A, Visvikis A, Paolicchi A, De Tata V and Casini AF: The changing faces of glutathione, a cellular protagonist. Biochem Pharmacol 66: 1499-1503, 2003.

27. Muthukumar K, Rajakumar S, Sarkar MN and Nachiappan V: Glutathione peroxidase3 of Saccharomyces cerevisiae protects phospholipids during cadmium-induced oxidative stress. Antonie van Leeuwenhoek 99: 761-771, 2011.

28. Nanji AA, Khettry U and Sadrzadeh SMH: Lactobacillus feeding reduces endotoxemia and severity of experimental alcoholic liver (disease). Exp Biol Med 205: 243-247, 1994.

29. Banerjee A and Dhar P: Amalgamation of polyphenols and probiotics induce health promotion. Crit Rev Food Sci Nutr 59: 2903-2926, 2019.

30. Cortés-Martín A, Selma MV, Tomás-Barberán FA, González-Sarrías A and Espín JC: Where to look into the puzzle of polyphenols and health? The postbiotics and gut microbiota associated with human metabotypes. Mol Nutr Food Res 64 e1900952, 2020

31. Soto-Alarcon SA, Valenzuela R, Valenzuela A and Videla LA: Liver protective effects of extra virgin olive oil: Interaction between its chemical composition and the cell-signaling pathways involved in protection. Endocr Metab Immune Disord Drug Targets 18: 75-84, 2018

32. Valenzuela R, Illesca $P$, Echeverría F, Espinosa A, Rincón-Cervera MA, Ortiz M, Hernandez-Rodas MC, Valenzuela A and Videla LA: Molecular adaptations underlying the beneficial effects of hydroxytyrosol in the pathogenic alterations induced by a high-fat diet in mouse liver: PPAR-o and Nrf2 activation, and NF- $\kappa$ B down-regulation. Food Funct 8: 1526-1537, 2017.
33. Hernández-Rodas MC, Valenzuela R, Echeverría $\mathrm{F}$, Rincón-Cervera MA, Espinosa A, Illesca P, Muñoz P, Corbari A, Romero N, Gonzalez-Mañan D and Videla LA: Supplementation with docosahexaenoic acid and extra virgin olive oil prevents liver steatosis induced by a high-fat diet in mice through PPAR- $\alpha$ and Nrf2 upregulation with concomitant SREBP-1c and NF- $\kappa$ B downregulation. Mol Nutr Food Res: 61, 2017 doi: $10.1002 / \mathrm{mnfr} .201700479$.

34. Bull-Otterson L, Feng W, Kirpich I, Wang Y, Qin X, Liu Y, Gobejishvili L, Joshi-Barve S, Ayvaz T, Petrosino J, et al: Metagenomic analyses of alcohol induced pathogenic alterations in the intestinal microbiome and the effect of Lactobacillus rhamnosus GG treatment. PLoS One 8: e53028, 2013.

35. Kim BK, Lee IO, Tan PL, Eor JY, Hwang JK and Kim SH: Protective effect of Lactobacillus fermentum LA12 in an alcohol-induced rat model of alcoholic steatohepatitis. Korean J Food Sci Anim Resour 37: 931-939, 2017.

36. Chiu WC, Huang YL, Chen YL, Peng HC, Liao WH, Chuang HL, Chen JR and Yang SC: Synbiotics reduce ethanol-induced hepatic steatosis and inflammation by improving intestinal permeability and microbiota in rats. Food Funct 6: 1692-1700, 2015.

37. Wang F, Zhang YJ, Zhou Y, Li Y,Zhou T,Zheng J, Zhang JJ, Li S, $\mathrm{Xu}$ DP and Li HB: Effects of beverages on alcohol metabolism: Potential health benefits and harmful impacts. Int J Mol Sci 17: 354, 2016.

38. Enomoto N, Yamashina S, Kono H, Schemmer P, Rivera CA, Enomoto A, Nishiura T, Nishimura T, Brenner DA and Thurman RG: Development of a new, simple rat model of early alcohol-induced liver injury based on sensitization of Kupffer cells. Hepatology 29: 1680-1689, 1999.

39. Klop B, do Rego AT and Cabezas MC: Alcohol and plasma triglycerides. Curr Opin Lipidol 24: 321-326, 2013.

40. Varella Morandi Junqueira-Franco M, Ernesto Troncon L, Garcia Chiarello P, do Rosário Del Lama Unamuno M, Afonso Jordao A and Vannucchi H: Intestinal permeability and oxidative stress in patients with alcoholic pellagra. Clin Nutr 25: 977-983, 2006

c) (i) $\odot$ This work is licensed under a Creative Commons

Attribution-NonCommercial-NoDerivatives 4.0 International (CC BY-NC-ND 4.0) License. 